\title{
Constructing ethanol-derived bioactive extracts using the brown seaweed Zonaria tournefortii (J.V.Lamouroux) Montagne performed with Timatic extractor by means of response surface methodology (RSM)
}

\author{
N. Nunes ${ }^{1,2}$ (D) S. Valente ${ }^{2} \cdot$ S. Ferraz ${ }^{1}$. Maria Carmo Barreto ${ }^{3}$ M.A.A. Pinheiro de Carvalho ${ }^{1}$ \\ Received: 7 June 2019 / Revised and accepted: 22 October 2019 / Published online: 28 November 2019 \\ (C) Springer Nature B.V. 2019
}

\begin{abstract}
Understanding the biochemical and antioxidant composition and capacity of a target biomass is the first step to its selectivity as functional food which can enhance the ability to promote health by reducing the risk of chronic diseases. The main purpose of this work was to employ response surface methodology (RSM) to determine the effect of the independent variables, $\%$ of ethanol (50-96\%), time of sonication (0-20 min), and number of extraction cycles (6-18 cycles) in the primary extract of brown seaweed Zonaria tournefortii, studying the yield variation of some bioactive compounds, assessing the potential of these bioextracts to integrate as a natural additives or supplements in the functional food industry. The extractions were performed employing "Green Chemistry" techniques executed with the Timatic extractor, which applied pressurized ethanol solution at a maximum pressure of 8.5 bar through milled dehydrated biomass in the extraction vessel. Several parameters were assessed in the primary bioactive extract which included extract yield (11.56-28.49 $\left.\mathrm{g}(100 \mathrm{~g})^{-1} \mathrm{dw}\right)$, total chlorophyll content $\left(0.14-1.42 \mathrm{~g}(100 \mathrm{~g})^{-1} \mathrm{dw}\right)$, total carotenoid content $(0.35-0.80 \mathrm{~g}$ $\left.(100 \mathrm{~g})^{-1} \mathrm{dw}\right)$, total fucoxanthin content $\left(0.04-0.13 \mathrm{~g}(100 \mathrm{~g})^{-1} \mathrm{dw}\right)$, total phenolic content $\left(3.58-5.84 \mathrm{~g}(100 \mathrm{~g})^{-1} \mathrm{dw}\right)$, total flavonoid content $\left(0.22-4.70 \mathrm{~g}(100 \mathrm{~g})^{-1} \mathrm{dw}\right)$, DPPH $(56.05-76.45 \%)$, and reducing activity $\left(3.83-6.04 \mathrm{~g}(100 \mathrm{~g})^{-1}\right.$ $\mathrm{dw})$. A second objective was to determine the suitability of the residue for subsequent extraction of valuable compounds such as fucoidan ( 4.87 to $\left.6.59 \mathrm{~g}(100 \mathrm{~g})^{-1} \mathrm{dw}\right)$ and cellulose (18.88 to $20.27 \mathrm{~g}(100 \mathrm{~g})^{-1} \mathrm{dw}$ ), implementing the first step to a biorefinery strategy, using a cascade approach.
\end{abstract}

Keywords Functional food $\cdot$ Bioactive extract $\cdot$ Biorefinery $\cdot$ Phaeophyceae $\cdot$ Fucoidan

Electronic supplementary material The online version of this article (https://doi.org/10.1007/s10811-019-01973-9) contains supplementary material, which is available to authorized users.

N. Nunes

nuno.nunes@staff.uma.pt

1 ISOPlexis Genebank, Faculty of Life Sciences, University of Madeira, Campus da Penteada, 9050-290 Funchal, Madeira, Portugal

2 UBQ II, Unidade de Bioquímica, Lda. Rua Visconde de Anadia, Edifício Anadia $5^{\circ}$ Andar CC, 9050-020 Funchal, Madeira, Portugal

3 cE3c-Centre for Ecology, Evolution and Environmental Changes/ Azorean Biodiversity Group and Faculty of Sciences and Technology, University of Azores, 9501-801 Ponta Delgada, Portugal

\section{Introduction}

Intensive research is conducted worldwide to increase knowledge concerning the integration and use of non-conventional food sources, of both terrestrial and marine origin, to improve the nutritional quality of food (Kumar et al. 2011). The understanding of the biochemical composition and antioxidant capacity of the target biomass is the first step to its selectivity as a functional food, promoting health benefits and reducing the risk of chronic diseases. Seaweeds represent an increasingly exploited excellent raw material for nutrients, food ingredients, and bioactive compounds (Kılınç et al. 2013). Intensive research concerning biorefinery strategy implementation to seaweed biomass has been published, in which this resource is introduced in a cascade extraction for multiple product production, increasing the biomass usability and reducing waste. 
Sustainable strategies for cascade extraction, linked to an efficient disintegration of biomass to obtain valuable biocompounds, can lead to a profitable industry (GilbertLópez et al. 2015). Kumar et al. (2013) used Gracilaria verrucosa, a red seaweed, to extract primarily agar and subsequently produce ethanol and a fertilizer, using the remaining biomass residue. Baghel et al. (2015) studied the implementation of a cascade extraction in 3 selected seaweeds, Gelidiella acerosa, Gelidium pusillum, and Gracilaria dura. Their research demonstrated that bioethanol could be efficiently produced from this biomass as a primary product and afterwards lipids, agar, phycobilins, and a liquid fertilizer could be extracted from the residual pulp. In a previous study (Nunes et al. 2018), we have studied the potential of the red seaweed Asparagopsis taxiformis integrated in a cascade extraction to primarily extract a bioactive extract followed by the extraction of lipids, carrageenan, and cellulose from the residue. The green seaweed, Ulva lactuca, was also studied by Bikker et al. (2016) who envisioned the production of a rich protein extract to be used as an animal feed. By applying an anaerobic fermentation to the hydrolysate, acetone, butanol, ethanol, and 1,2-propanediol also could be produced. Kostas et al. (2017) also demonstrated that the brown seaweed Laminaria digitata has potential to be a valuable source of alginates and fucoidan. Furthermore, a waste liquor, which demonstrated antioxidant and antimicrobial activity, was obtained as a byproduct and finally ethanol could be produced through fermentation.

In the present study, Zonaria tournefortii, a common brown seaweed present in the south shore of Madeira island, was the target seaweed. In a previous work, we characterized seven macroalgae collected in Madeira Archipelago, including Z. tournefortii which demonstrated the highest antioxidant activity and lipid content (Nunes et al. 2017). The main objective of this work was to determine the variation of some bioactive compounds, in a primary extract of the brown seaweed $Z$. tournefortii, when varying three independent variables (\% of ethanol, time of sonication, and number of extraction cycles) according to the Box-Behnken design. A second objective was to determine the suitability of the residue for subsequent extraction of two valuable biocompounds, fucoidan and cellulose, implementing a biorefinery strategy, using a cascade approach.

\section{Materials and methods}

\section{Seaweed biomass}

Zonaria tournefortii (J.V.Lamouroux) Montagne samples were collected in a $10-\mathrm{m}$ maximum depth dive of the Madeiran south coastline (coordinates 32,646,95116,823,967). Samples were collected in August 2016 and were transported in seawater and gently rinsed with filtered fresh water to remove salt and debris. Afterwards, primary drying was applied in which seaweed was frozen at $-35^{\circ} \mathrm{C}$ and freeze-dried under reduced pressure $\left(4 \times 10^{-4} \mathrm{mbar}\right)$, with a cooling trap set at $-56^{\circ} \mathrm{C}$ for 5 days. Samples were milled to 200 mesh particle size, vacuum-packed, and stored at $-35^{\circ} \mathrm{C}$ until use.

\section{Experimental design and statistical analysis}

Optimization of extraction conditions was performed using STATISTICA 10.0 software for Windows, adopting a BoxBehnken design, with three factors and three levels of secondorder regression. The number of experiments was calculated according to Eq. 1:

$N=k^{2}+k+c p$

where $k$ is the factor number and $c p$ is the replicate number of the central points. This resulted in 15 experimental runs with three central points. The parameters and levels employed were 50,73 , and $96 \%$ ethanol extractions, time of sonication $(0,10$, and $20 \mathrm{~min}$ ), and Timatic cycle extractions $(6,12$, and 18 cycles). These independent variables were assessed in order to determine the maximum yield of several parameters used to evaluate the primary extract. A response surface methodology (RSM) was employed and fitted to a second-order polynomial model, according to Eq. 2:

$Y=\beta_{0}+\sum_{i=1}^{3} \beta_{i} X_{i}+\sum_{i=1}^{3} \beta_{i i} X_{i}+\sum \sum_{i<j=1}^{3} \beta_{i j} X_{i} X_{j}$

where $Y$ is the predicted response, $\beta_{0}$ is the constant coefficient, $\beta_{i}$ is the linear coefficient, $\beta_{i i}$ is the quadratic coefficient, $\beta_{i j}$ is the cross product coefficient, and $X_{i}$ and $X_{j}$ are independent variables. The statistical method of RSM is used for optimizing several industrial processes.

In order to visualize the correlation between the response and the independent variables, the fitted polynomial regression equations were expressed graphically. Analysis of variance (ANOVA) was performed to distinguish significant differences between dependent variables $(p<0.05)$. Twodimensional contour plots were developed, while holding one variable constant in the second-order polynomial model. The validity of the model was determined by comparing the experimental and predicted values.

\section{Preparation of ethanol "Green Chemistry" extracts}

Extractions were performed with 50,73, or 96\% ethanol, using a Timatic semiautomatic extractor (Technolab, Spello, Italy; represented in Fig. 1), set at a constant 
Fig. 1 Timatic micro-extractor schematic diagram. (A) Sample vessel. (B) Active pressure piston. (C) Secondary pressure piston. (D) Discharge. (E) Discharge/circulation. (F) Pump. (G) Pneumatic valve. (H) Electronic display and access buttons. (I) Printer

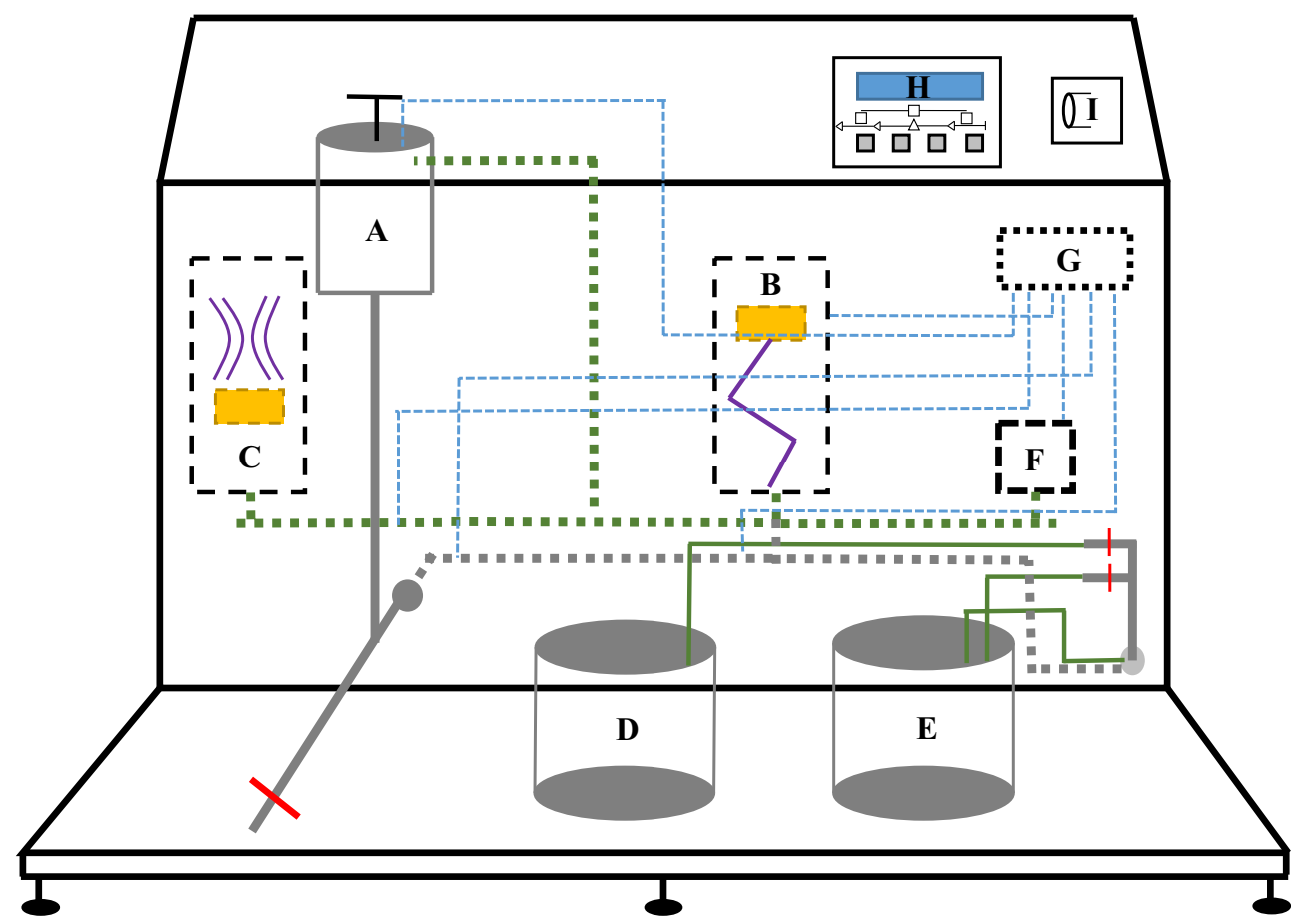

pressure and static phase. Program was set as follows: solvent capacity $1 \mathrm{~L}$, solvent to biomass ratio 50:1, compression time $3 \mathrm{~min}$, decompression time $6 \mathrm{~min}$, minimum pressure 6 bar, compression pressure 8.5 bar at room temperature $\left( \pm 23{ }^{\circ} \mathrm{C}\right)$. Total process time varied with the number of cycles: 6 cycles ran for 54 min, 12 cycles for $108 \mathrm{~min}$, and 18 cycles for $162 \mathrm{~min}$. Twenty (20) gram samples were placed in a $100-\mu \mathrm{m}$ pore bag and placed inside a $0.5-\mathrm{L}$ extracting vessel. At the end of each extraction, extracts were filtered through $11 \mu \mathrm{m}$ Whatman filter, partly evaporated in a rotary evaporator, and dehydrated completely in an oven, at $40{ }^{\circ} \mathrm{C}$. Zonaria tournefortii extracts were subjected to analysis of eight parameters at a concentration of $1 \mathrm{mg} \mathrm{mL}{ }^{-1}$. The postextracted algal residue (PEAR) was recovered and dried in an oven at $40{ }^{\circ} \mathrm{C}$, for further downstream assessment. Both extracts and PEAR were stored under vacuum at $35{ }^{\circ} \mathrm{C}$ until use.

\section{Extract analysis}

\section{Total phenolic content}

Total phenolic content (TPC) was determined using the Folin Ciocalteu method described by Chew et al. (2008), adding 1.5 $\mathrm{mL}$ of Folin Ciocalteu's phenol reagent to $1.2 \mathrm{~mL}$ of $\mathrm{Na}_{2} \mathrm{CO}_{3}$ $(7.5 \% \mathrm{w} / \mathrm{v})$ and then adding $0.3 \mathrm{~mL}$ of the sample extract $\left(1 \mathrm{mg} \mathrm{mL}^{-1}\right)$. The reaction mixture was incubated in the dark for $30 \mathrm{~min}$ and the absorbance was measured at $765 \mathrm{~nm}$. Results were expressed as grams of gallic acid equivalents
(GAE) per $100 \mathrm{~g}$ in dry weight (dw) of extract. The calibration equation for gallic acid was $Y=0.0076853 x+0.069\left(R^{2}=\right.$ 0.9969).

\section{Pigment measurements}

Total chlorophyll, carotenoids, and fucoxanthin content in $Z$. tournefortii extracts were determined through the equations described in Verma et al. (2017). These were assessed in triplicate and equations were as follows:

Total Chlorophyll $\left(\frac{\mu \mathrm{g}}{\mathrm{mL}}\right)=20.2\left(\mathrm{~A}_{645}\right)+8.02\left(\mathrm{~A}_{663}\right)$

Carotenoids $\left(\frac{\mathrm{mg}}{\mathrm{g}}\right)=4.2\left(\mathrm{OD}_{452.5}\right)-(0.0264(\mathrm{Chl} a))$

$$
+(0.426(\mathrm{Chl} b))
$$

Fucoxanthin $\left(\frac{\mathrm{mg}}{\mathrm{g}}\right)$

$$
=\mathrm{A}_{470}-1.239\left(\mathrm{~A}_{631}+\mathrm{A}_{581}-0.3\left(\mathrm{~A}_{664}\right)\right)-0.0275\left(\mathrm{~A}_{664}\right) / 141
$$

\section{Total flavonoid content}

The total flavonoid content (TFC) of $Z$. tournefortii extracts was determined by the aluminum chloride colorimetry test according to Chan et al. (2015). Initially, $0.5 \mathrm{~mL}$ of sample $\left(1 \mathrm{mg} \mathrm{mL}^{-1}\right)$ or standard was stirred with $1.5 \mathrm{~mL}$ of methanol, 
$0.1 \mathrm{~mL}$ of aluminum chloride (10\%), $0.1 \mathrm{~mL}$ of $1 \mathrm{M}$ potassium acetate, and $2.8 \mathrm{~mL}$ of distilled water. The mixture was then incubated for $30 \mathrm{~min}$ in the dark at room temperature. Readings were carried out in a Shimadzu PC-2401 spectrophotometer at $415 \mathrm{~nm}$ and quercetin was used as a standard, ranging from 0.05 to $0.15 \mathrm{mg} \mathrm{mL}^{-1}$. The results were expressed as grams of quercetin equivalent (QE) per $100 \mathrm{~g}$ $\mathrm{dw}$ of extract (g QE $\left.(100 \mathrm{~g})^{-1} \mathrm{dw}\right)$. The calibration equation for quercetin was $Y=0.0059 x-0.0225\left(R^{2}=0.9955\right)$. All measurements were performed in triplicate.

\section{Free radical-scavenging assay (DPPH)}

For the DPPH assay, the 2,2-diphenylpicrylhydrazyl stable radical was used following the methods described by Yen and Chen (1995) and Duan et al. (2006) with modifications. An aliquot of $2 \mathrm{~mL}$ of freshly prepared $0.16 \mathrm{mM}$ methanolic solution of DPPH was added to $2 \mathrm{~mL}$ of seaweed extract $\left(1 \mathrm{mg} \mathrm{mL}{ }^{-1}\right)$ solution. The mixture was vortexed for $1 \mathrm{~min}$ and then left to stand at room temperature for $30 \mathrm{~min}$ in the dark. Readings were accomplished in a Shimadzu PC-2401 spectrophotometer at $517 \mathrm{~nm}$. An equal amount of methanol and DPPH served as control and ascorbic acid was used as positive control. All measurements were performed in triplicate. The result was calculated and expressed as $\%$ of radical scavenging.

\section{\%Radical Scavenging}

$$
=\left[1-\left(\frac{\mathrm{A}_{\text {sample }}-\mathrm{A}_{\text {sample blank }}}{\mathrm{A}_{\text {control }}}\right)\right] \times 100
$$

where the $A$ control is the absorbance of the control (DPPH solution without sample), the $A$ sample is the absorbance of the test sample (DPPH solution plus test sample), and the $A$ sample blank is the absorbance of the sample (sample without DPPH solution).

\section{Reducing activity}

The reducing activity (RA) assay was determined following the method of Oyaizu (1986) and Yuan et al. (2005) with modifications. A volume of $1.25 \mathrm{~mL}$ of potassium phosphate buffer $(0.2 \mathrm{M}, \mathrm{pH} 6.6)$ was added to an equal volume of potassium hexacyanoferrate at $1 \%(\mathrm{w} / \mathrm{v})$. This solution was mixed with $0.5 \mathrm{~mL}$ of extract at $1 \mathrm{mg} \mathrm{mL}{ }^{-1}$. The reaction mixture was incubated in a water bath at $50{ }^{\circ} \mathrm{C}$ for $20 \mathrm{~min}$. Afterwards, $1.25 \mathrm{~mL}$ trichloroacetic acid $(10 \%$, w/v) $1.25 \mathrm{~mL}$ water, and $0.25 \mathrm{~mL}$ ferric chloride hexahydrate $(0.1 \%$, w/v $)$ were added to $1.25 \mathrm{~mL}$ of the reaction mixture. The solution was incubated at room temperature, during $10 \mathrm{~min}$ for color development, in the dark. The absorbance was measured at $700 \mathrm{~nm}$ in a Shimadzu PC-2401 spectrophotometer. The RA value was expressed as grams of ascorbic acid equivalents (AAE) per $100 \mathrm{~g}$ of $\mathrm{dw}$. The calibration equation for ascorbic acid was $Y=0.0121 x+0.0047\left(R^{2}=0.9996\right)$.

\section{Downstream product analysis}

To assess the potential of a downstream extraction, the seaweed PEAR (post-extracted algal residue) was dried in an oven at $40{ }^{\circ} \mathrm{C}$ and weighed. PEAR was subjected to two extraction procedures, using a cascade approach, firstly extracting fucoidan and secondly cellulose.

\section{Fucoidan extraction}

After the primary extraction, PEAR was used for fucoidan extraction. This method was followed according to ChaleDzul et al. (2015) with modifications. Two grams of dried residue was initially extracted with $50 \mathrm{~mL}$ of ethanol $(1: 25$, $\mathrm{w} / \mathrm{v})$ at $80 \%(\mathrm{v} / \mathrm{v})$ at $70{ }^{\circ} \mathrm{C}$ for $12 \mathrm{~h}$. The residue was separated from the supernatant and used in the following extractions. Three aqueous extractions, using distilled water with a biomass:water ratio of 2:25 (w/v), were performed, with primary extraction conducted at room temperature for $7 \mathrm{~h}$, followed by a second extraction for $7 \mathrm{~h}$ at $70{ }^{\circ} \mathrm{C}$ and finally a third extraction for $4 \mathrm{~h}$ at $70^{\circ} \mathrm{C}$. The aqueous extracts were pooled and the residue kept and dried at $40{ }^{\circ} \mathrm{C}$ for subsequent cellulose extraction. The liquid was treated with calcium chloride $(2 \mathrm{M})$ at room temperature in order to precipitate alginates. After alginate removal by centrifugation at $10,000 \mathrm{rpm}$ for $30 \mathrm{~min}$, the supernatant was dialyzed for $48 \mathrm{~h}$ to decrease salinity, changing distilled water every $12 \mathrm{~h}$. Resulting extracts were freeze-dried, analyzed in a ATR-FTIR spectra analyzer, and compared with fucoidan obtained by direct extraction from the biomass and with standard fucoidan extracted from Fucus vesiculosus ( $\geq 95 \%$ purity) purchased from Sigma-Aldrich.

\section{Cellulose extraction}

After fucoidan extraction, the remaining residue was integrated in the final biorefinery step to perform the cellulose extraction. The methodology was adapted from Baghel et al. (2015) with modifications. Initially, this residue was soaked in acetate buffer $(1: 15, \mathrm{w} / \mathrm{v})$ containing $36 \%$ of sodium chlorite. The mixture was bleached at $60{ }^{\circ} \mathrm{C}$ for $8 \mathrm{~h}$. Afterwards, samples were washed with water until neutrality and treated with sodium hydroxide $(0.5 \mathrm{M})$ solution $(1: 6, \mathrm{w} / \mathrm{v})$ at $60^{\circ} \mathrm{C}$ for $12 \mathrm{~h}$. Afterwards, the mixture was washed with water until neutrality, re-suspended in hydrochloric acid at 5\% (1:4, w/v), and heated up to boiling $\left(100^{\circ} \mathrm{C}\right)$, maintaining it for $5 \mathrm{~min}$. This mixture was left to rest overnight at room temperature, washed with water to remove acid excess, and dried. The obtained cellulose was then characterized with ATR-FTIR and 
compared with cellulose directly extracted from the starting biomass.

\section{Spectroscopic analysis}

The samples' ATR-FTIR spectra were obtained with a Perkin Elmer Spectrum Two, coupled to a Diamond ATR (DurasamplIR II, Smiths Detection, UK). Thirty-two scans were acquired in transmittance mode (spectra range 4000$650 \mathrm{~cm}^{-1}$ ), with a wave resolution of $1 \mathrm{~cm}^{-1}$. All samples were analyzed in triplicates for all tests carried out.

\section{Results and discussion}

\section{Box-Behnken design}

The experimental design matrix (Table 1) was constructed using Box-Behnken design (BBD), with three factors (ethanol $\%$, sonication time, and number of cycles) and three levels ($1,0,1)$ in a second-order regression (Eq. 1), resulting in 15 runs with 3 center points $(0,0,0)$. This set of experiments allowed us to determine the extraction conditions that produce a significant effect in the extracts' bioactivity and to understand how the biocompounds are influenced. The percentage of ethanol varied from 50 to $96 \%$, mixed with distilled water; previous sonication of sample was performed from 0 to $20 \mathrm{~min}$ and the Timatic extractor functioned between 6 and 18 cycles. The BBD is a spherical model, with all points describing a sphere not containing any point at the vertices of the cubic region created by the maximum and minimum limits of each variable. This design is advantageous when the points on the corners of the cube determine factor level combinations impossible to test. The BBD employed in this work enabled the prediction of the biocompounds in the bioextract (Supplement Table A), varying the independent variables (factor levels). The prediction of the bioactive compounds includes extract yield (yield), total chlorophyll content (TChlC), total carotenoid content (TCC), total fucoxanthin content (TFxC), total phenolic content (TPC), and total flavonoid content (TFC). Also, two dependent variables were integrated for antioxidant assessment, free radical-scavenging assay (DPPH), and reducing activity (RA).

\section{Influence of the independent variables in the biocompounds}

Yield values (Supplement Table A) were higher with 50\% ethanol extractions $\left(28.49 \mathrm{~g}(100 \mathrm{~g})^{-1} \mathrm{dw}\right)$ and decrease in an inverse correlation with the increase of ethanol percentage, reaching its minimum with $96 \%$ ethanol $\left(11.60 \mathrm{~g}(100 \mathrm{~g})^{-1}\right.$ $\mathrm{dw})$. For TChlC, TCC, TFxC, TPC, and TFC, the highest values were obtained when performing the extraction with $96 \%$ ethanol, reaching $1.41,0.79,0.13,5.81$, and $4.34 \mathrm{~g}$ $(100 \mathrm{~g})^{-1} \mathrm{dw}$, respectively. A direct correlation was determined between the percentage of ethanol used to perform the extraction and the yield of these biocompounds in the bioactive extract, reaching its lowest content when performing the extraction with $50 \%$ ethanol, wherein TChlC, TCC, TFxC, TPC, and TFC were $0.14,0.35,0.04,3.63$, and $0.45 \mathrm{~g}(100$ $\mathrm{g})^{-1} \mathrm{dw}$. The DPPH did not show this linear behavior since the highest antioxidant capacity was demonstrated in the bioactive extract performed with $96 \%$ ethanol $(76.01 \%)$ and the lowest when performing the extract using $73 \%$ ethanol $(56.85 \%)$, when performing the free radical-scavenging assay. The highest values for RA were obtained when the
Table 1 Box-Behnken design (BBD) for 3 factors (independent variables, $\mathrm{A}, \mathrm{B}$, and $\mathrm{C}$ ) with 3 levels $(-1,0,+1)$. Design resulted in 15 runs with 3 left points $(0,0,0)$. Ethanol used was 50,73, or $96 \%$. The selected number of cycles in the Timatic was 6,12 , or 18. The extraction was subjected to 0,10 , or $20 \mathrm{~min}$ of sonication

\begin{tabular}{llll}
\hline Run & $($ A) Ethanol $(\%)$ & $(\mathrm{B})$ Cycles $\left(n^{\circ}\right)$ & $(\mathrm{C})$ Sonication $(\mathrm{min})$ \\
\hline $1(+1,-1,0)$ & $96(+1)$ & $6(-1)$ & $10(0)$ \\
$2(-1,-1,0)$ & $50(-1)$ & $6(-1)$ & $10(0)$ \\
$3(-1,0,-1)$ & $50(-1)$ & $12(0)$ & $0(-1)$ \\
$4(+1,0,+1)$ & $96(+1)$ & $12(0)$ & $20(+1)$ \\
$5(0,0,0)$ & $73(0)$ & $12(0)$ & $10(0)$ \\
$6(0,0,0)$ & $73(0)$ & $12(0)$ & $10(0)$ \\
$7(-1,+1,0)$ & $50(-1)$ & $18(+1)$ & $10(0)$ \\
$8(-1,0,+1)$ & $50(-1)$ & $12(0)$ & $20(+1)$ \\
$9(+1,+1,0)$ & $96(+1)$ & $18(+1)$ & $10(0)$ \\
$10(+1,0,-1)$ & $96(+1)$ & $12(0)$ & $0(-1)$ \\
$11(0,-1,+1)$ & $73(0)$ & $6(-1)$ & $20(+1)$ \\
$12(0,-1,-1)$ & $73(0)$ & $6(-1)$ & $0(-1)$ \\
$13(0,+1,+1)$ & $73(0)$ & $18(+1)$ & $20(+1)$ \\
$14(0,0,0)$ & $73(0)$ & $12(0)$ & $10(0)$ \\
$15(0,+1,-1)$ & $73(0)$ & $18(+1)$ & $0(-1)$ \\
\hline
\end{tabular}


extractions were performed with 50\% ethanol (5.88 g (100 $\mathrm{g})^{-1} \mathrm{dw}$ ), decreasing to minimal values when $73 \%$ ethanol $\left(3.87 \mathrm{~g}(100 \mathrm{~g})^{-1} \mathrm{dw}\right)$ was used.

\section{Statistical model analysis}

An ANOVA analysis was done to determine the relationship between the response and significant variables with $95 \%$ confidence with 0.05 significance level. High $F$ values associated with low $p$ values, generally less than 0.05 , indicate that this model could be used to predict the biocompound responses. $p$ values greater than 0.05 indicate that the specific variable, integrated in the model, cannot be predicted accurately. In the statistical analysis of model (Supplement Table B), all $F$ values and respectively $p$ values were considered acceptable except for TFxC $(p$ value $=0.072)$ and TFC $(p$ value $=0.064)$. The lack-of-fit performance analysis indicates the goodness of fit, and $p$ values greater than 0.05 (non-significant) suggest that there is no lack of fit. This statistical test indicated that all of the dependent variables were adequate for this model and could predict the responses accurately, except for TFxC $(p$ $=0.016$ ).

\section{Correlation matrix}

A correlation matrix was obtained (Supplement Table C), in which the analysis demonstrated the relation between individual parameters. Significant negative statistical correlations were found between yield and TPC $(-0.96)$, TChlC ($0.92)$, TCC $(-0.82)$, TFxC $(-0.78)$, and TFC $(-0.74)$. Moreover, TChlC also had significant positive correlations between TPC (0.91), TFxC (0.88), TCC (0.86), and TFC (0.83). TCC demonstrated the same behavior with TFxC (0.96), TFC (0.82), and TPC (0.80). TFxC had additional statistical significant correlations with TFC $(0.80)$ and TPC (0.79). Additionally, TPC demonstrated some correlation with TFC (0.72). These high correlation coefficients evidence that selected model has good relationship between the response and independent variables.

\section{Model optimization}

Graphical analysis of the response surface was determined (data not shown), plotting firstly the ethanol \% vs. the number of cycles (constant $10 \mathrm{~min}$ of sonication), secondly the ethanol \% vs. the time of sonication (constant of 12 cycles), and thirdly the number of cycles vs. the time of sonication (constant $73 \%$ ethanol), to predict optimal extracting conditions for all parameters used. These constants (10 min sonication, 12 cycles in the Timatic extractor, and $73 \%$ ethanol for extraction) correspond to the central level of each factor. For extraction yield, the RSM clearly predicts that the percentage of ethanol is inversely correlated with extract yield. Lower percentage of ethanol used to produce the extract will correspond to higher yields due to the usage of water as a co-solvent. Water has higher dielectric constant than ethanol, 80 and 25 at $20^{\circ} \mathrm{C}$, respectively, thus representing higher polarity (Mohsen-Nia et al. 2010). Water can increase the density of the fluid mixture and cause swelling of the solid particles, improving the diffusion and thereby the solubilization of polysaccharides (Saravana et al. 2017). Higher extract yield could be achieved, performing the extraction exclusively under higher sonication time or alternatively increasing the number of cycles. The optimization of the independent variables enables maximum values for the studied parameters (Supplement Table D). The reducing activity (RA) is also higher when the ethanol percentage is $50 \%$. This means that when targeting an extract with a higher antioxidant capacity with this specific activity, a lower percentage of ethanol would be preferable, reducing ethanol costs. For the extraction of the remaining biocompounds, the highest ethanol percentage (96\%) is preferable. The extraction cycles could be significantly reduced for almost all of the biocompounds studied, except for DPPH and TChlC, reducing the time of extraction. Furthermore, the previous sonication performed to the biomass with the correspondent extract solvent could be neglected when targeting TCC and TPC or reduced to 8 or 13 min when higher DPPH and RA activity are preferable, respectively. The optimization of the conditions to perform the extract enables to target specific characteristics, reducing costs, time of extraction, and equipment usage. Plotting all independent variables, in order to determine the best conditions (total desirability) of the overall extraction (Fig. 2), these were found to be $96 \%$ ethanol, 14.4 cycles, and 20 min sonication, in which desirability value reached 0.72 with a maximum value of 1 .

\section{Model validation}

The mean, minimum, maximum, and standard deviation for each individual extraction parameter were determined (Supplement Table E). The goodness of the model and RSM was verified using the multiple $R, R^{2}$, and adjusted $R^{2}$ correlation coefficients. The correlation coefficients for yield, TChlC, TPC, and RA varied from 1 to a minimum of 0.9. These were found to possess the highest correlation between predicted and experimental values (Supplement Table A). For TCC, TFxC, and DPPH, the correlation coefficients oscillated from 0.95 and a minimum of 0.84 . The lowest correlation found was in TFC which varied from 0.91 to a minimum of 0.77 . In all parameters, the predicted correlation was in close agreement with the adjusted coefficient of correlation. 

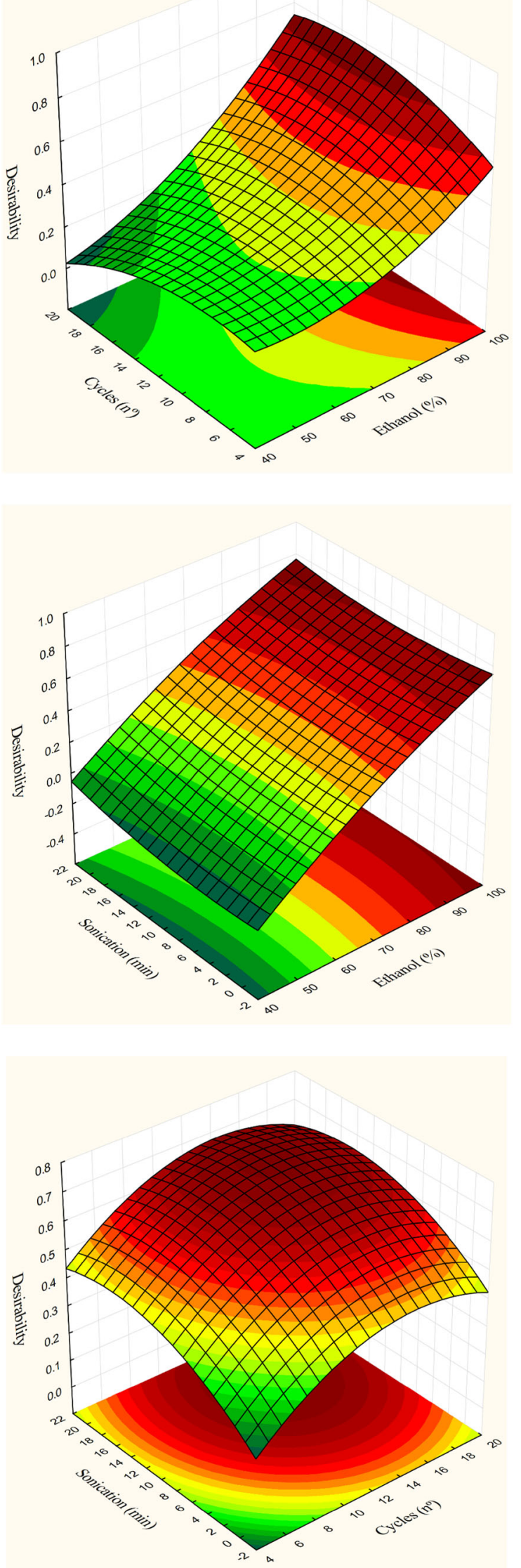

Fig. 2 Desirability surface plots, using quadratic fit methodology, for the statistical assessment of the biochemical and antioxidant assays. Overall desirability was 0.72 for the designed model

\section{Model predictability}

Surface plots were performed to predict the behavior and identify important relationships between the dependent variables. Five relevant relationships were found, which enabled a comprehensive understanding of how these parameters are linked.

In Fig. 3(A), a linear increase of TFxC can be visualized when TChlC and TCC increase simultaneously. TFxC reaches the highest value, $0.17 \mathrm{~g}(100 \mathrm{~g})^{-1} \mathrm{dw}$, when TChlC and TCC are 1.6 and $0.9 \mathrm{~g}(100 \mathrm{~g})^{-1} \mathrm{dw}$, respectively. Also, higher values of TFxC $\left(0.14 \mathrm{~g}(100 \mathrm{~g})^{-1} \mathrm{dw}\right)$ is achieved when TChlC and TPC are at their maximum values, 1.6 and $6.0 \mathrm{~g}$ $(100 \mathrm{~g})^{-1} \mathrm{dw}$, respectively (presented in Fig. 3(B)). Again, higher TFxC value is achieved also when TPC and TFC are at their maximum value, 6.0 and $5.0 \mathrm{~g}(100 \mathrm{~g})^{-1} \mathrm{dw}$, respectively (presented in Fig. 3(C)). These results demonstrate that higher TChlC, TCC, TPC, and TFC values are preferable when constructing extracts with higher fucoxanthin contents. Furthermore, higher TPC values in the extract were found when higher TChlC and lower TCC values are present (Fig. 3(D)). TPC could reach $7.0 \mathrm{~g}(100 \mathrm{~g})^{-1} \mathrm{dw}$ when TChlC is at $1.6 \mathrm{~g}(100 \mathrm{~g})^{-1} \mathrm{dw}$ and TCC $0.3 \mathrm{~g}(100 \mathrm{~g})^{-1} \mathrm{dw}$. Plotting TPC against TFC (Fig. 3(E)), it can be determined that DPPH percentage achieves maximum (100\% of scavenging activity) when TPC is at its maximum value of $6.0 \mathrm{~g}(100 \mathrm{~g})^{-1} \mathrm{dw}$ and TFC at minimum value. This result means that the scavenging activity in the extract is not influenced by flavonoids but possibly by other phenolic compounds present in the extract.

\section{Cascade approach}

The PEAR residue was reserved for the downstream extractions. This biorefinery effort was applied to create a possibility to overcome an industrial problem which is the high input of biomass, large discharge of residue, and low profitability. Several scientific studies concerning this effort were recently published. Bikker et al. (2016) assessed a biorefinery strategy for the green macroalga Ulva lactuca. They performed an aqueous treatment and an enzymatic hydrolysis at $50{ }^{\circ} \mathrm{C}$, primarily extracting a protein-rich fraction, which could be used for animal feed. Applying an anaerobic fermentation to the liquid extract, they determined that biofuels, acetone, butanol, ethanol, and 1,2-propanediol could be obtained. Also, Magnusson et al. (2016) studied Ulva ohnoi and Ulva tepida to integrate in a biorefinery effort, primarily extracting seaweed salts, dehydrating the water used to wash these macroalgae and hypothesized the use of the remaining biomass to produce compost, used for crop production, and feed 

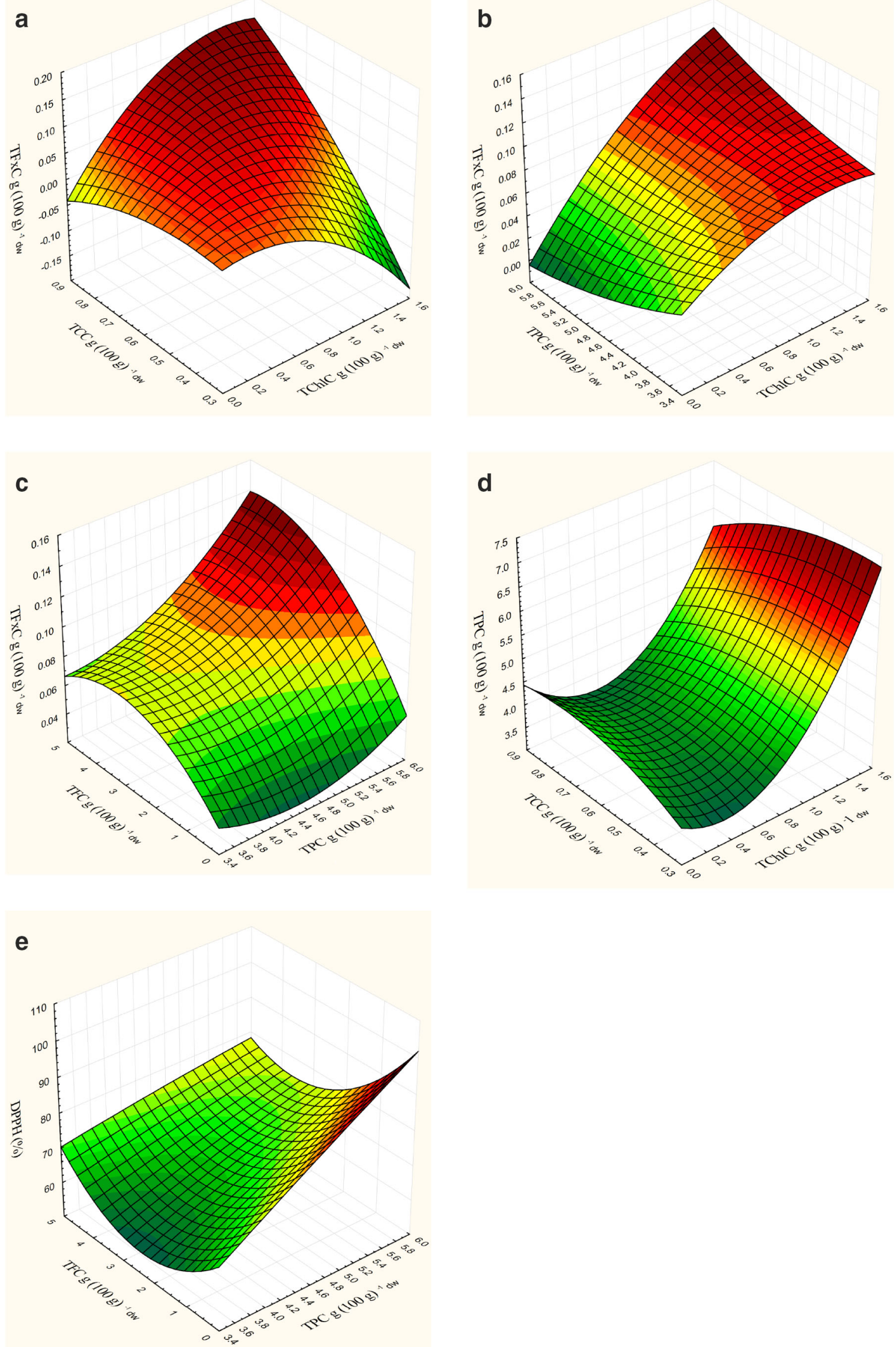
Fig. 3 Surface plots with color scale for quantity. Values are described in grams $(100 \mathrm{~g})^{-1} \mathrm{dw}$ except for DPPH which is presented in $\%$ of antioxidant capacity. (A) TFxC (Z) against TChlC (X) and TCC (Y), equation TFxC $=-0.0164-0.0786 * x+0.2592 * y-0.1152 * x * x+$ $0.4313 * x * y-0.319 * y^{*} y$; (B) TFxC (Z) against TChlC (X) and TPC $(\mathrm{Y})$, equation $\mathrm{TFxC}=0.2045-0.0056^{*} x-0.0598^{*} y-0.0301^{*} x^{*} x+$ $0.0235 * x * y+0.0042 * y * y$; (C) TFxC (Z) against TPC (X) and TFC (Y), equation $\mathrm{TFxC}=0.232-0.0922 * x+0.0113 * y+0.0103 * x * x+$ $0.0046^{*} x^{*} y-0.0042^{*} y^{*} y$; (D) TPC (Z) against TChlC (X) and TCC $(\mathrm{Y})$, equation TPC $=2.4294-1.1033 * x+5.6895 * y+2.387 * x * x-$ $1.8531 * x^{*} y-3.8494^{*} y^{*} y$; (E) DPPH (Z) against TPC (X) and TFC $(\mathrm{Y})$, equation DPPH $=19.2021+15.2059^{*} x-3.2193^{*} y-0.2388^{*} x^{*} x$ $-1.982 * x * y+2.0789 * y * y$

mill utilized for animal production or to produce biocrude for renewable fuels.

The methodology presented in this work intends to assess the quantity of crude fucoidan and cellulose that can be extracted from PEAR. Each time PEAR was exposed to an extraction protocol, the residue was dehydrated, ground, and weighed to assess the real yield that can be obtained from the subsequent residue. Also, to assess the lost biomass using this biorefinery strategy, Table 2 was performed. The initial biomass, used to perform the extraction, was $20 \mathrm{~g}$ from which the highest bioactive extract content $(5.7 \mathrm{~g})$ originated from performing the extract with the lowest ethanol percentage in the extraction solvent (50\%). Moreover, higher yield of crude fucoidan was extracted from the $73 \%$ and $96 \%$ ethanolderived residue $(1.3 \mathrm{~g})$ and cellulose from the $50 \%$ ethanolremaining residue $(4.0 \mathrm{~g})$. The lost or unused biomass varied from 8.4 to $10.9 \mathrm{~g}$, from which higher losses resulted from the primary usage of the highest ethanol percentage in the extraction solvent $(96 \%)$.

\section{Fucoidan}

The fucoidan crude extract from PEAR of $Z$. tournefortii was quantified between $4.87 \pm 0.33$ and $6.59 \pm 0.43 \mathrm{~g}$ $(100 \mathrm{~g})^{-1} \mathrm{dw}$, presented in Table 3, for the 50 and $73 \%$ ethanol previous extractions, respectively. Fucoidan extracted from whole seaweed Z. tournefortii was $5.66 \pm$ $0.45 \mathrm{~g}(100 \mathrm{~g})^{-1} \mathrm{dw}$. PEAR from 73 and $96 \%$ ethanol extracts gave $6.59 \pm 0.43$ and $6.38 \pm 0.21 \mathrm{~g}(100 \mathrm{~g})^{-1}$ $\mathrm{dw}$, respectively, presenting more fucoidan than the
Table 3 Downstream extracted products from PEAR. Extracted and purified yield of fucoidan and cellulose, represented in grams $(100 \mathrm{~g})^{-1}$ in $\mathrm{dw}$ for the direct extraction from biomass and from PEAR $(50,73$, and $96 \%$ ethanol-remaining residue)

\begin{tabular}{lll}
\hline & $\begin{array}{l}\text { Fucoidan yield } \\
\left(\mathrm{g}(100 \mathrm{~g})^{-1} \mathrm{dw} \pm \mathrm{SD}\right)\end{array}$ & $\begin{array}{l}\text { Cellulose yield } \\
\left(\mathrm{g}(100 \mathrm{~g})^{-1} \mathrm{dw} \pm \mathrm{SD}\right)\end{array}$ \\
\hline Direct extraction & $5.66 \pm 0.45$ & $8.75 \pm 0.13$ \\
$50 \%$ ethanol & $4.87 \pm 0.33$ & $20.24 \pm 0.10$ \\
$73 \%$ ethanol & $6.59 \pm 0.43$ & $20.27 \pm 0.15$ \\
$96 \%$ ethanol & $6.38 \pm 0.21$ & $18.88 \pm 0.26$ \\
\hline
\end{tabular}

seaweed biomass. This fact is due to the fucoidan enrichment in the residue, when performing a previous selective extraction to the seaweed biomass, resulting in a more concentrated source of fucoidan. It comprises fucoseenriched sulfated polysaccharides with a high degree of complexity. They are present in the fibrillar cell wall as structural molecules and in the intercellular spaces of brown seaweeds reinforcing tissue cohesion. Several biological activities can be attributed to fucoidan, including antioxidant, anti-inflammatory, antithrombotic, anticoagulant, and antivirus, and also possess effect against various renal, hepatic, and uropathic disorders (Senthilkumar et al. 2013). Nowadays, it is used as an additive in a few products such as healthy food, drinks, and cosmetics (Pádua et al. 2015). Fletcher et al. (2017) assessed 3 seaweeds from the coast of Aberystwyth (UK) and found that the percentage of fucoidan was 7.5, 8.9, and 12.2 for Fucus serratus, Ascophyllum nodosum, and Fucus vesiculosus, respectively. Skriptsova et al. (2010) determined that the yield of fucoidan extracted from Undaria pinnatifida, collected from Peter the Great Bay (Russia) from April until July, oscillated between 3.21 and $16.00 \mathrm{~g}(100 \mathrm{~g})^{-1} \mathrm{dw}$, depending on the month of collection. Yuan and Macquarrie (2015) assessed a biorefinery strategy, using A. nodosum, collected in the coast of Shetland as a starting biomass, which determined that fucoidan yield could reach up to $14.09 \mathrm{~g}(100 \mathrm{~g})^{-1} \mathrm{dw}$. Laminaria digitata, collected in Cornwall, England, was also integrated in a biorefinery strategy application (Kostas et al. 2017), in which crude fucoidan was primarily extracted in

Table 2 Biorefinery efficiency

\begin{tabular}{lllllll}
\hline $\begin{array}{l}\text { \% of ethanol in the } \\
\text { extraction solution }\end{array}$ & $\begin{array}{l}\text { Initial } \\
\text { biomass } \\
\text { weight }(\mathrm{g})\end{array}$ & $\begin{array}{l}\text { Moisture } \\
(\mathrm{g})\end{array}$ & $\begin{array}{l}\text { Biomass } \\
\text { extract } \\
\text { weight }(\mathrm{g})\end{array}$ & $\begin{array}{l}\text { Crude } \\
\text { fucoidan } \\
\text { weight }(\mathrm{g})\end{array}$ & $\begin{array}{l}\text { Crude } \\
\text { cellulose } \\
\text { weight }(\mathrm{g})\end{array}$ & $\begin{array}{l}\text { Unused } \\
\text { biomass } \\
(\mathrm{g})\end{array}$ \\
\hline 50 & 20 & 0.8 & 5.7 & 1.0 & 4.0 & 8.5 \\
73 & 20 & 0.8 & 5.4 & 1.3 & 4.1 & 8.4 \\
96 & 20 & 0.8 & 3.2 & 1.3 & 3.8 & 10.9 \\
\hline
\end{tabular}

Data are mean values. Assessment of the biorefinery efficiency when performing the proposed cascade extraction, firstly removing a bioactive extract, followed by crude fucoidan and cellulose extraction 
which yield reached $6.55 \mathrm{~g}(100 \mathrm{~g})^{-1} \mathrm{dw}$, similar to this work.

The ATR-FTIR analysis of standard fucoidan purified from $F$. vesiculosus $(\geq 95 \%)$, purified fucoidans resulting from the direct seaweed extraction and from PEAR extracts, was performed (Fig. 4). Fifteen important bands were detected from 650 to $4000 \mathrm{~cm}^{-1}$ and used for fucoidan evaluation. IR absorption at $694 \mathrm{~cm}^{-1}$ (band 1) possibly indicates a twisting movement of C-O linkage. At $836 \mathrm{~cm}^{-1}$ (band 2), an intense peak due to a symmetric C-O-S bending vibration of sulfate substitutes at axial C-4 position was observed. Absorption of
IR occurring at $920 \mathrm{~cm}^{-1}$ (band 3) could indicate a rocking vibration of $\mathrm{CH}_{3}$, peak at $974 \mathrm{~cm}^{-1}$ (band 4), an antisymmetric vibration of C-O-S and a rocking vibration of $\mathrm{CH}_{3}$. An intense peak at $1009 \mathrm{~cm}^{-1}$ (band 5), shoulder at $1048 \mathrm{~cm}^{-1}$ (band 6), small peak at $1137 \mathrm{~cm}^{-1}$ (band 7) and a more intense peak at $1158 \mathrm{~cm}^{-1}$ (band 8 ) could be due to the stretching in a pyranoid ring and C-O-C stretching of glycosidic bonds. An intense peak of IR absorption at $1222 \mathrm{~cm}^{-1}$ (band 9) is a characteristic peak for fucoidan, due to the vibration of $\mathrm{S}=\mathrm{O}$ linkage. A shoulder present in band 9 with $1256 \mathrm{~cm}^{-1}$ (band 10) could indicate an asymmetric $\mathrm{O}=\mathrm{S}=\mathrm{O}$ stretching vibration

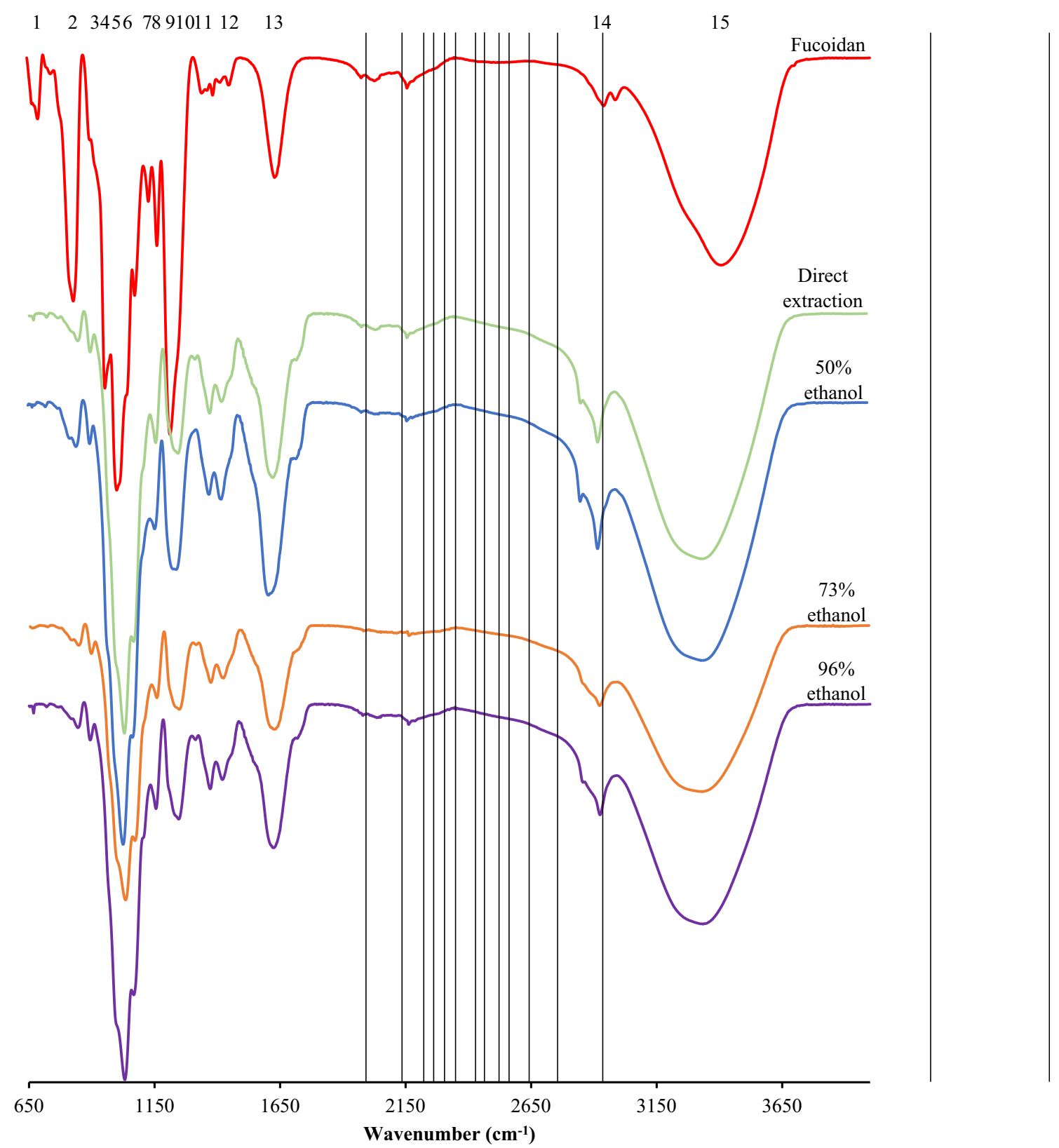

Fig. 4 ATR-FTIR spectra, plotting wavenumber $\left(\mathrm{cm}^{-1}\right)$ by transmittance $(\%)$, of fucoidan extracted using Chale-Dzul et al. (2015) methodology of whole seaweed (direct extraction) or from PEAR (50,73, and 96\% ethanol-remaining residue) and comparing with fucoidan standard 
of sulfate esters. Small intensity peaks at $1380 \mathrm{~cm}^{-1}$ (band 11) might be due to symmetric bending vibrations of $\mathrm{CH}_{3}$ and at $1455 \mathrm{~cm}^{-1}$ (band 12), scissoring vibrations of $\mathrm{CH}_{2}$ and asymmetric vibrations of $\mathrm{CH}_{3}$. At wavelength $1635 \mathrm{~cm}^{-1}$ (band 13), a medium intensity peak was detected and could be due to the asymmetric stretching of carboxylate vibration. At 2948 $\mathrm{cm}^{-1}$ (band 14) wavenumber, a low intensity peak aroused and could be attributed to C-H stretching. At $3417 \mathrm{~cm}^{-1}$ (band $15)$, an intense band was detected and is characteristic of water presence in the fucoidan extract and standard.

\section{Cellulose extraction}

The cellulose extracted from PEAR varied from $18.88 \pm 0.26$ to $20.27 \pm 0.15 \mathrm{~g}(100 \mathrm{~g})^{-1} \mathrm{dw}$ (presented in Table 3) for the $96 \%$ and $73 \%$ ethanol-remaining residues, respectively. The cellulose yield from whole $Z$. tournefortii was determined to be $8.75 \pm 0.13 \mathrm{~g}(100 \mathrm{~g})^{-1} \mathrm{dw}$. The cellulose extracted from PEAR was about 2 times higher than from the direct extraction. The reason of the higher ratio is due to an increase in cellulose concentration in PEAR, which resulted from selective extractions of other compounds, as referred above for fucoidan. Each time another compound was extracted from the initial PEAR, it was dried, ground, and weighed, and each time, cellulose was concentrated in the final PEAR. Cellulose extracted from seaweeds has long polymeric chains that could be hydrolyzed to produce nanocellulose (Chen et al. 2016). It has potential to be introduced in several applications being the production of films with barrier properties, biocomposites, and systems for controlled drug deliver and release as some examples (Ditzel et al. 2017). Siddhanta et al. (2009) determined 12 seaweed species from India, in which cellulose varied from 2.5 to $12.5 \%$, demonstrating the potential that PEAR has for selectively extract and purify cellulose. In a previous work (Nunes et al. 2018), we have demonstrated the applicability of a biorefinery strategy to the red macroalgae $A$. taxiformis, in which $21.65 \mathrm{~g}(100 \mathrm{~g})^{-1} \mathrm{dw}$ of cellulose could be extracted from the residue, when performing the initial extraction using ethanol.

The ATR-FTIR analysis technique developed a fingerprint spectra for the cellulose purified from Z. tournefortii (Fig. 5). Eleven important bands were identified from 650 to 4000 $\mathrm{cm}^{-1}$ and used for comparison. The decrease of transmittance $\%$ at $902 \mathrm{~cm}^{-1}$ (band 1) was a consequence of glycosidic linkages between the anhydroglucose rings in the cellulose. IR absorption from $1000 \mathrm{~cm}^{-1}$ (band 2) to $1031 \mathrm{~cm}^{-1}$ (band 3) could be attributed to C-O-C bending. At $1055 \mathrm{~cm}^{-1}$ (band 4), a reduction of transmittance could be detected and assigned to the vibration of C-O-C pyranose ring skeleton and at 1160 $\mathrm{cm}^{-1}$ (band 5) due to C-O-C asymmetric stretching of cellulose. Transmittance reduction at $1428 \mathrm{~cm}^{-1}$ (band 6) could be attributed to $\mathrm{C}-\mathrm{H}$ bending and at $1641 \mathrm{~cm}^{-1}$ (band 7), IR absorbed could be due to $\mathrm{O}-\mathrm{H}$ bending in water molecules. Peak at $1735 \mathrm{~cm}^{-1}$ (band 8) could be attributed to $\mathrm{C}=\mathrm{O}$ and peak at $2162 \mathrm{~cm}^{-1}$ (band 9) could be due to stretch in triple bonds between carbons. A sp3 C-H stretching vibration was identified at $2899 \mathrm{~cm}^{-1}$ (band 10) and a stretching of O-H was responsible for IR absorption and consequent decrease of
Fig. 5 ATR-FTIR spectra, plotting wavenumber $\left(\mathrm{cm}^{-1}\right)$ by transmittance (\%), of cellulose extracted using Baghel et al. (2015) methodology of whole seaweed (direct extraction) or from PEAR (50, 73, and 96\% ethanol-remaining residue)

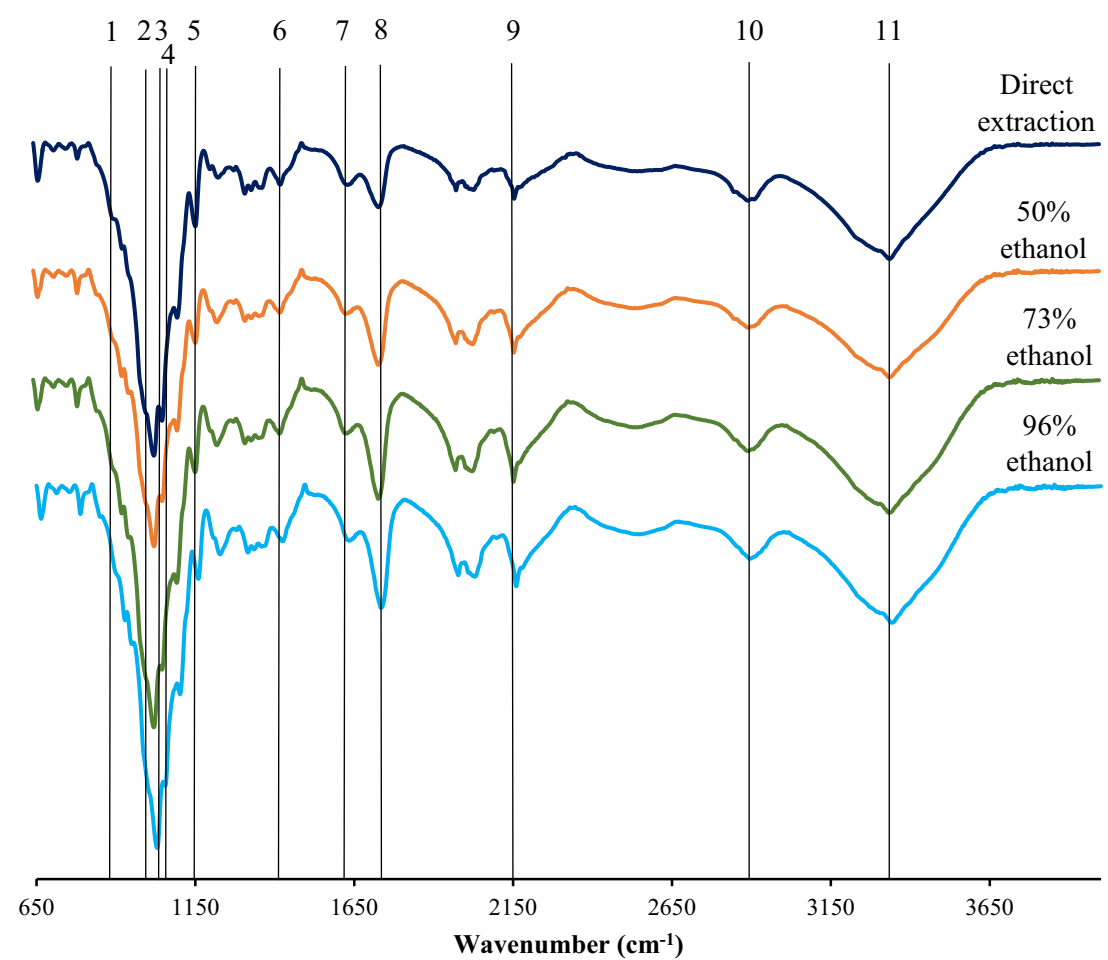


transmittance $\%$ at $3343 \mathrm{~cm}^{-1}$ (band 11) due to some water present in the purified cellulose.

\section{Conclusions}

The outcome of this work enabled us to understand the usefulness of the Timatic equipment to produce a bioactive extract, using the macroalgae $Z$. tournefortii, applying a BBD to increase efficiency. An overall prediction suggests that higher yield of biocompounds and antioxidant activity is obtained in the primary extract, when performing the extraction with higher ethanol percentages, although extract yield showed an opposite behavior. These extracts could be further purified to obtain specific compounds. For example, purified fucoxanthin and phenolic compounds could be further purified from this primary extract, since these are value-added products, known for their bioactive capabilities, which potentiates their integration in food products as natural antioxidants. Furthermore, these extracts could be considered as a whole for nutraceutical applications, optimizing the extraction to increase or decrease specific compounds or activities. Further studies would be necessary to firstly test the potential of these extracts in specific bioactivities in vitro, followed by in vivo assessments. The cascade approach allowed an evaluation of the extractability and purification potential of fucoidan and cellulose in the remaining biomass residue. Fucoidan yield of $Z$. tournefortii was found to be lower than that from some reported works, but this lower value could be attributed to the collection period, since it has been reported that these values tend to be superior in macroalgae collected in autumn and winter. The reason could be attributed to the presence of fucoidan in the fibrillar cell wall as a reinforcement molecule, possibly to support stronger currents and movement in these periods. This biocompound could be efficiently extracted from PEAR, increasing income and reducing waste, since this product could be commercialized as a nutraceutical or food supplement due to several positive bioactivities already reported in previous works. Also, cellulose yield extracted from PEAR presented higher values than the direct extraction from the biomass and other reported works, evidencing the PEAR potential for cellulose extraction and purification. Cellulose could be further purified to be integrated in value-added products such as an excipient in food supplements or as nanocellulose, used to produce cosmetics and aerogels, between other numerous applications. ATR-FTIR analysis allowed the comparison of fucoidan and cellulose with direct extractions from the biomass and standard. The obtained spectra were essential to determine the key IR absorptions that distinguish these compounds and revealed to be very close to the direct extractions from the biomass and in the case of fucoidan, similar to its standard.
Funding information This work was financially supported by ISOPlexis, Faculty of Life Sciences, University of Madeira, through the following projects: DemoBlueAlgae, M1420-01-0247-FEDER000002, program PROCiência 2020; MACBIOBLUE, MAC/1.1b/ 086, program INTERREG MAC 2014-2020; and ARDITI - Regional Agency for the Development of Research Technology and Innovation and UBQ II, Unidade de Bioquímica (UBQ II company), through the program of PhD scholarships in Business, M14-20-09-5369-FSE-000001Doctorate. Authors also present their acknowledgment to DRCT (Azores Regional Government) for funding Azorean Biodiversity Group (ABG), the FCT-Fundação para a Ciência e a Tecnologia, through Portuguese National Funds, and the FEDER through the PT2020 Partnership Agreement, UID/BIA/00329/2013, 2015-2018, UID/BIA/ $00329 / 2019$ funding the cE3c center.

\section{References}

Baghel RS, Trivedi N, Gupta V, Neori A, Reddy CRK, Lali A, Jha B (2015) Biorefining of marine macroalgal biomass for production of biofuel and commodity chemicals. Green Chem 17:2436-2443

Bikker P, van Krimpen MM, van Wikselaar P, Houwelling-Tan B, Scaccia N, van Hal JW, Huijgen WJJ, Cone JW, López-Contreras AM (2016) Biorefinery of the green seaweed Ulva lactuca to produce animal feed, chemicals and biofuels. J Appl Phycol 28:35113525

Chale-Dzul J, Moo-Puc R, Robledo D, Freile-Pelegrín Y (2015) Hepatoprotective effect of the fucoidan from the brown seaweed Turbinaria tricostata. J Appl Phycol 27:2123-2135

Chan PT, Matanjun P, Yasir SM, Tan TS (2015) Antioxidant activities and polyphenolics of various solvent extracts of red seaweed, Gracilaria changii. J Appl Phycol 27:2377-2386

Chen YW, Lee HV, Juan JC, Phang SM (2016) Production of new cellulose nanomaterial from red algae marine biomass Gelidium elegans. Carbohydr Polym 151:1210-1219

Chew YL, Lim YY, Omar M, Khoo KS (2008) Antioxidant activity of three edible seaweeds from two areas in South East Asia. LWTFood Sci Technol 41:1067-1072

Ditzel FI, Prestes E, Carvalho BM, Demiate IM, Pinheiro LA (2017) Nanocrystalline cellulose extracted from pine wood and corncob. Carbohydr Polym 157:1577-1585

Duan XJ, Zhang WW, Li XM, Wang BG (2006) Evaluation of antioxidant property of extract and fractions obtained from a red alga, Polysiphonia urceolata. Food Chem 95:37-43

Fletcher HR, Biller P, Ross AB, Adams JMM (2017) The seasonal variation of fucoidan within three species of brown macroalgae. Algal Res 22:79-86

Gilbert-López B, Mendiola JA, Fontecha J, van den Broek LAM, Sijtsma L, Cifuentes A, Hererro M, Ibáñez E (2015) Downstream processing of Isochrysis galbana: a step towards microalgal biorefinery. Green Chem 17:4599-4609

Kılınç B, Cirik S, Turan G, Tekogul H, Koru E (2013) Seaweeds for food and industrial applications. In: Muzzalupo I (ed) Food industry. InTech, London, pp 735-748

Kostas ET, White DA, Cook DJ (2017) Development of a bio-refinery process for the production of speciality chemical, biofuel and bioactive compounds from Laminaria digitata. Algal Res 28:211-219

Kumar M, Gupta V, Kumari P, Reddy CRK, Jha B (2011) Assessment of nutrient composition and antioxidant potential of Caulerpaceae seaweeds. J Food Compos Anal 24:270-278

Kumar S, Gupta R, Kumar G, Sahjoo D, Kuhad RC (2013) Bioethanol production from Gracilaria verrucosa, a red alga, in a biorefinery approach. Bioresour Technol 135:150-156 
Magnusson M, Carl C, Mata L, de Nys R, Paul NA (2016) Seaweed salt from Ulva: a novel first step in a cascading biorefinery model. Algal Res 16:308-316

Mohsen-Nia M, Amiri H, Jazi B (2010) Dielectric constants of water, methanol, ethanol, butanol and acetone: Measurement and computational study. J Solut Chem 39:701-708

Nunes N, Ferraz S, Valente S, Barreto MC, Pinheiro de Carvalho MAA (2017) Biochemical composition, nutritional value, and antioxidant properties of seven seaweed species from the Madeira Archipelago. J Appl Phycol 29:2427-2437

Nunes N, Ferraz S, Valente S, Barreto MC, Pinheiro de Carvalho MAA (2018) Nutraceutical potential of Asparagopsis taxiformis (Delile) Trevisan extracts and assessment of a downstream purification strategy. Heliyon 4:e00957

Oyaizu M (1986) Studies on products of browning reaction. Antioxidative activities of products of browning reaction prepared from glucosamine. Japanese J Nutr Diet 44:307-315.

Pádua D, Rocha E, Gargiulo D, Ramos AA (2015) Bioactive compounds from brown seaweeds: phloroglucinol, fucoxanthin and fucoidan as promising therapeutic agents against breast cancer. Phytochem Lett 14:91-98

Saravana PS, Getachew AT, Cho YJ, Choi JH, Park YB, Woo HC, Chun BS (2017) Influence of co-solvents on fucoxanthin and phlorotannin recovery from brown seaweed using supercritical $\mathrm{CO}_{2}$. J Supercrit Fluids 120:295-303

Senthilkumar K, Manivasagan P, Venkatesan J, Kim SK (2013) Brown seaweed fucoidan: biological activity and apoptosis, growth signaling mechanism in cancer. Int J Biol Macromol 60:366-374
Siddhanta AK, Prasad K, Meena R, Prasad G, Mehta GK, Chhatbar MU, Oza MD, Kumar S, Sanandiya ND (2009) Profiling of cellulose content in Indian seaweed species. Bioresour Technol 100:66696673

Skriptsova AV, Shevchenko NM, Zvyagintseva TN, Imbs TI (2010) Monthly changes in the content and monosaccharide composition of fucoidan from Undaria pinnatifida (Laminariales, Phaeophyta). J Appl Phycol 22:79-86

Verma P, Kumar M, Mishra G, Sahoo D (2017) Multivariate analysis of fatty acid and biochemical constitutes of seaweeds to characterize their potential as bioresource for biofuel and fine chemicals. Bioresour Technol 226:132-144

Yen G-C, Chen H-Y (1995) Antioxidant activity of various tea extracts in relation to their antimutagenicity. J Agric Food Chem 43:27-32

Yuan YV, Carrington MF, Walsh NA (2005) Extracts from dulse (Palmaria palmata) are effective antioxidants and inhibitors of cell proliferation in vitro. Food Chem Toxicol 43:1073-1081

Yuan Y, Macquarrie DJ (2015) Microwave assisted step-by-step process for the production of fucoidan, alginate sodium, sugars and biochar from Ascophyllum nodosum through a biorefinery concept. Bioresour Technol 198:819-827

Publisher's note Springer Nature remains neutral with regard to jurisdictional claims in published maps and institutional affiliations. 